\title{
The development of oral motor control and language
}

\author{
Katie Alcock \\ Department of Psychology, Lancaster University
}

\begin{abstract}
Motor control has long been associated with language skill, in deficits, both acquired and developmental, and in typical development. Most evidence comes from limb praxis however; the link between oral motor control and speech and language has been neglected, despite the fact that most language users talk with their mouths. Oral motor control is affected in a variety of developmental disorders, including Down syndrome. However, its development is poorly understood. We investigated oral motor control in three groups: adults with acquired aphasia, individuals with developmental dysphasia, and typically developing children. In individuals with speech and language difficulties, oral motor control was impaired. More complex movements and sets of movements were even harder for individuals with language impairments. In typically developing children (21-24 months), oral motor control was found to be related to language skills. In both studies, a closer relationship was found between language and complex oral movements than simple oral movements. This relationship remained when the effect of overall cognitive ability was removed. Children who were poor at oral movements were not good at language, although children who were good at oral movements could fall anywhere on the distribution of language abilities. Oral motor skills may be a necessary precursor for language skills.
\end{abstract}

Keywords: oral motor control, language development, developmental language disorders, gesture

\section{Evidence for a link between motor control and language}

In examining the relationship between motor control and language development and disorders, there is a contrast between the large amount that is known about limb motor control and the small amount that is known about oral motor control. For example, it has long been known that the first stages of language development occur in parallel with the first stages of gesture development, and that children whose first gestures are earlier than average usually also say their first words earlier than average (Bates et al., 1979). Recent data also show that children who are late in the onset of both spontaneous communicative gesture and spoken language are more likely to remain delayed than those who start making com- municative gestures at a typical age but whose speech is also delayed (Thal et al., 1997). There is also a strong association between limb motor control difficulties and language impairment (Hill, 2001), which appear to share a common genetic basis (Bishop, 2002). This imbalance in research exists despite the fact that the majority of language users speak, rather than sign. We now turn to work on the development of oral motor skills.

\section{Oral motor development}

There has been little work to date on how oral motor control develops in children, and much of this has been concentrated on the feeding behaviour of young infants or developmentally disabled children (a selection of recent work includes Fucile et al., 2005; Johnson \& Harris, 2004; Mason et al., 2005; Rogers \& Arvedson, 2005), with no investigation of any possible link to language 
development. Some studies purporting to examine oral motor control and language focus on diadochokinesis, the ability to repeat speech syllables as fast as possible, which seems to stray from the definition of nonverbal oral motor skill, and which also has questionable value in diagnosis of oral praxis difficulties (Yaruss \& Logan, 2002).

Given this background, we are not yet sure, for example, when children might reach adult functional levels of oral motor skill. For example, Landt and Ingervall (1975) suggest that an adult level of skill may not be reached by 11 years, while more speech-like aspects of development may reach their adult level around 14 years (Smith \& Zelaznik, 2004). In contrast, other authors suggest that mature skill levels may be reached at a much younger age (Stark \& Blackwell, 1997).

\section{Associations in disorders}

Much of the research into the relationship between nonverbal oral motor control and language development has been inspired by a multiplicity of studies showing that language dysfunction and oral motor dysfunction often occur together. My own research shows similar patterns of impairment in developmental and acquired verbal dyspraxia (Alcock et al., 2000b, see also details below). Indeed, generally acquired oral dyspraxia and acquired nonfluent dysphasia are found to be associated (Mateer \& Kimura, 1977). Although dissociations between these two have been found (Masdeu \& O'Hara, 1983), the association is common enough to suggest a link of some kind; dissociations in adult acquired dysfunction do not necessarily suggest modularity in development (Karmiloff-Smith, 1998).

Oral motor skill is found to be impaired in many developmental disorders where spoken language is also impaired: it is commonly impaired in autism (Adams, 1998; Amato \& Slavin, 1998; Page \& Boucher, 1998); oral motor difficulties are more commonly found in autistic children than limb motor difficulties. Oral motor control has frequently been found to be impaired in Down syndrome, and this seems to stem not just from oral weaknesses but to involve some degree of dyspraxia (Kumin \& Adams, 2000; Kumin \& Bahr, 1999; Spender et al., 1995). In children with specific language impairment (SLI), very few studies have looked at oral motor control but in those that have, associations have been found. For example, Stark and Blackwell (1997) found that oral motor skills were associated with both nonword repetition and phoneme identification in SLI.

There has in particular been a suggestion that developmental verbal dyspraxia cannot exist without nonverbal, oral dyspraxia (Stackhouse \& Snowling, 1992). With these associations in mind, study 1 investigated the oral motor abilities of a group of individuals with a developmental speech and language impairment, the KE family.

\section{Study 1 - Oral motor control in developmental and acquired speech and language impairment}

Specific speech and language impairment seems to occur in between $2-7 \%$ of children, who have no global learning disability, sensory impairment, or social impairment such as an autistic spectrum disorder, which might explain their language delay. Strictly speaking, individuals with SLI should have nonverbal IQ in the normal range. There is much evidence that SLI can be genetic and the KE family follows this pattern. This family has around 30 members in three generations of whom $50 \%$ have a speech and language impairment, and the pattern of inheritance seems to be dominant, with full penetrance (Fisher et al., 1998).

The KE family's language skills were first reported by Gopnik and Crago (1991), who suggested they had specific problems with formation of regular past tense forms, and in particular that they had no significant articulation problem past childhood; Pinker (1995) went on to claim that the family did not resemble adult aphasic individuals in their language or other abilities. However, Vargha-Khadem et al., (1995) found that affected family members had difficulty with both regular and irregular past tense, that other grammatical structures were impaired, as well as most other tests of speech and language, and that affected family members had lower IQ scores than unaffected family members. These findings suggested that nonverbal skills might also be affected. In addition to oral motor skill (Alcock et al., 2000b), musical pitch and timing skills were investigated (Alcock et al., 2000a). Because of the common finding of oral motor difficulties in individuals with acquired speech and language impairment, a group of such individuals with acquired left hemisphere (LH) lesions were included. In addition, there was the possibility that there might be some bilateral neural deficits in affected family members, and indeed evidence has emerged for this (Watkins et al., 2002), as well as for some right hemisphere involvement in oral praxis (Bizzozero et al., 2000). A group of individuals with analogous acquired right hemisphere (RH) lesions were therefore included. Eleven affected family members (mean age 21.1, SD 15.7) were compared with 56 age-matched controls (mean age 25.8, SD 20.8), and likewise older adults with acquired unilateral lesions (nine $\mathrm{LH}$, mean age 57.44 , SD 18.27 , ten $\mathrm{RH}$, mean age 63.00, SD 7.52) were compared with 23 older age- and 
years-of-education-matched controls (mean age 61.96, SD 10.28)

\section{Test details}

The oral motor tasks used here are administered by a tester seated opposite the participant, who videotapes the testing session for later scoring. Each set of movements is first administered to command and secondly to imitation. There are four sets of movements: Simple movements, involving only one set of muscles (example: open the mouth); Complex movements involving more than one set of muscles (example: whistle); Temporal sequences of movements, involving three movements, one after the other (example: first open the mouth, then stick out the tongue, then say "Ah"); Parallel (or simultaneous) movements, involving three movements simultaneously (example: all at the same time, open the mouth, stick out the tongue, and say "Ah"). Details of the movements used can be found in Alcock (1995).

\section{Results}

Details of the differences between affected family members, individuals with acquired unilateral lesions, and age-matched controls can be found in Alcock et al., (2000b). In summary, the affected family members performed worse overall, and even worse on the more complex conditions - single complex movements, and combinations of movements. Imitation aided performance for all subjects and aided performance more on the more complex conditions but the effect of this was no different for the affected family members than for the age-matched controls. The same pattern of results was seen for the participants with acquired aphasia. The individuals with acquired RH lesions performed more poorly than age-matched controls, but not even more poorly on harder movements. There was no difference between affected family members and age-matched controls on simple, single movements performed either to imitation or command, and likewise the individuals with acquired aphasia performed at the same level as controls on these simple, single movements to imitation but more poorly to command. The performance of the two languageimpaired groups and the age-matched controls can be seen in Figure 1.

\section{Discussion}

Overall the affected family members are impaired in their performance of oral movements - apart from simple single movements. The harder the movements become, the larger the difference between the participants with either developmental or acquired language impairments, and their control subjects. The pattern of impairment for the two groups is very similar. This impairment is unlikely to be due to language comprehension difficul-
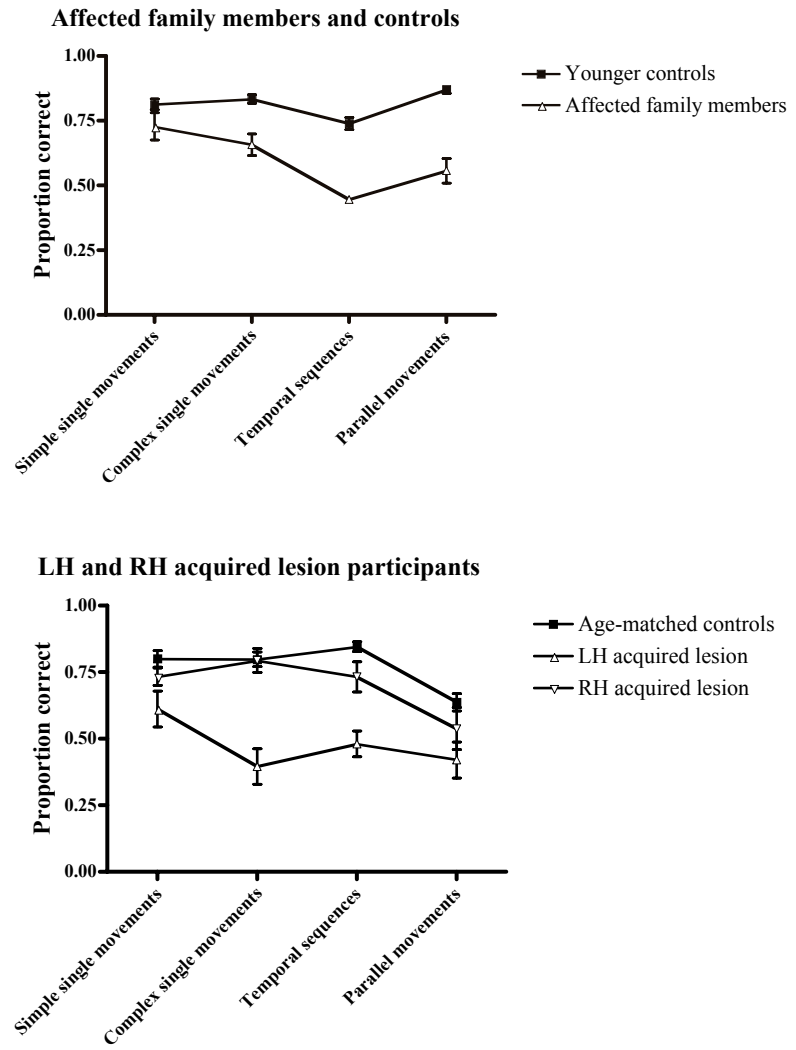

Figure 1. Performance of language impaired groups and controls on oral motor tasks

ties, as movements which were imitated were impaired as well as those that were performed to command; imitation improved performance equally for all subjects, not differentially for those with language difficulties.

From this, and other data (Alcock et al., 2000a), it can be seen that the affected family members have pervasive nonverbal deficits, as well as their wide-ranging language difficulties. Although the majority of family members do have IQ scores within the typical range, and could therefore be classified as having specific language impairment, this family is not entirely similar to many individuals with SLI, in that some affected family members have lower IQ scores and could not necessarily be classified as having specific language impairment, and also in that most affected family members (Gopnik \& Crago, 1991, notwithstanding) can be clearly identified by most listeners as having speech coordination difficulties - as being dyspraxic. This very obvious difficulty is not found in many older children and adults with a history of SLI, who nonetheless have real difficulties with language. However, some studies find that children who have an identifiable speech impairment when they are younger can go on to have solely 'language' difficulties when they are older (Felsenfeld et al., 1992; Lewis et al., 2004). Although it may be possible to identify more 
older children and adults who have similar concurrent language difficulties and oral motor difficulties, it may be that these oral motor difficulties are more likely to be found in younger children, and it is also possible that these could be the precursor to a language difficulty. This possibility led to study 2 .

\section{Study 2 - Oral motor control in typical language development}

\section{Background}

The average age at which children undergo a burst in vocabulary development, and start to combine words into sentences, is 21 months (Bates et al., 1995). As this is the fastest point of development, and the point of greatest individual differences, this is an ideal time-point at which to examine individual differences in oral motor and language skill.

Briefly, a variety of explanations have been put forward for the sudden increase in vocabulary development and its association with grammatical development. Werker et al., (2002) suggest that an improvement in word perception may lead to this change, whereas Naigles (1990) hypothesises that syntax assists word learning. The idea that the same neural network underlies both grammatical and lexical development is put forward by Elman et al., (1996), and in a similar explanation, Bates and Goodman (1997) argue that grammar is part of lexicon so that children necessarily learn both together. It is important, therefore, to examine associations of oral motor control with both lexical and grammatical development.

What, then, do we know about associations between these two skills in typical development? There is in fact very little data on this link. Moore and Ruark (Moore \& Ruark, 1996) used EMG recordings to examine the coordination of activity in feeding behaviour and speech motor behaviour, and suggested that these were not linked. However, the types of motor activity examined in the non-speech category in this study were mainly those involving a single set of muscles - opening and closing the mouth, chewing etc. - which were not found to be impaired in individuals with language impairments in Study 1. A small body of research finds immature oromotor function and immature speech processes difficult if not impossible to separate, even up to 10 years (Qvarnstrom et al., 1994). We set out to investigate this link further. If such a link is found at the time of the vocabulary burst, would it, as with associations with language disorders, be dependent on the difficulty of the movements used? Would there be any particular association with vocabulary, or with grammar? Would such a link merely be dependent on some level of general maturity, which might also be shown in gross motor development, or in cognitive development?

\section{Test and participant details}

As in Study 1, a test was devised which involved the experimenter sitting with the child and videoing their movements for later scoring. At this young age, however, children are not capable of responding to instructions involving oral movements so the movements were all demonstrated by the experimenter, and where possible props were provided to help the child understand what was required as part of the movement. Again, simple movements involving only one set of muscles (example: opening the mouth, with a puppet to copy) and complex movements involving more than one set of muscles (example: licking the lips, with honey to lick off the lips) were used. Speeded, repeated movements (example: open and close the mouth as fast as possible, copying the puppet) were also used, although sequences and combinations of movements were not used with this age group. Details of the movements used can be found in the Appendix. Children's language skills were assessed using the Macarthur-Bates CDI (Fenson et al., 1994), which parents complete, and which includes questions directed at children's expressive vocabulary and at their use of increasingly complex word combinations and grammatical morphemes. Cognitive development was assessed using the Parent-based Assessment of Cognitive Abilities (PARCA - Saudino et al., 1998), and gross motor development using the Bayley Scales of Infant Development (Bayley, 1993).

Twenty-four infants aged 20.5 to 21.5 months were assessed, $($ mean $=21.1, \mathrm{SD}=.25$, comprising 18 boys 6 girls). The infants were recruited from the local maternity ward at birth for infant research, and were all full term, with no diagnosis of developmental disorder or hearing loss, and with English the only language spoken in the home.

\section{Results}

The overall correlation between the total score on the oral motor battery and the total vocabulary as measured on the CDI was not significant $(r=.293)$. However, complex, simple, and repeated movements had different relationships to language skills in previous studies (Alcock \& Gordon, 2002; Alcock et al., 2000b), and a specific relationship between grammatical vocabulary and oral motor skill was also found in previous research with typically developing 24-month olds (Alcock \& Gordon, 2002). Table 1 shows the correlations between content words, function words, and complexity (a rough measure of MLU), and scores for simple, complex, and repeated movements. It can be seen that the score for complex oral movements correlates significantly with all measures of 


\begin{tabular}{lccc}
\hline & $\begin{array}{l}\text { Total content } \\
\text { words used }\end{array}$ & $\begin{array}{l}\text { Total function } \\
\text { words used }\end{array}$ & $\begin{array}{l}\text { Sentence } \\
\text { complexity score }\end{array}$ \\
\hline $\begin{array}{l}\text { Oral motor total score } \\
\begin{array}{l}\text { Complex oral movements } \\
\text { total score }\end{array}\end{array}$ & 0.266 & 0.361 & 0.225 \\
$\begin{array}{l}\text { Repeated movements } \\
\text { total score }\end{array}$ & $0.495^{*}$ & $0.531^{*}$ & $0.452^{*}$ \\
\hline$* p<.05$ & -0.251 & -0.155 & -0.326 \\
\hline
\end{tabular}

\section{Table 1. Correlations between oral motor skill and language use}

language. Figure 2 shows the relationship between complex oral motor skill and total vocabulary.

It could be possible, however, that this correlation is due to a general maturity or cognitive ability factor: children who are good at language are also good at everything else. In fact, oral motor skills correlate significantly with the child's score on the Bayley Scales (Motor) ( $r=.517, p$ $=.011$ ). However, Bayley (Motor) scores do not correlate significantly with children's vocabularies $(\mathrm{r}=.172, p>$ $.05)$.

Oral motor skills also correlate significantly with children's scores on the PARCA $(\mathrm{r}=.564, p=.005)$, and the correlation between the PARCA and total vocabulary approaches significance $(\mathrm{r}=.406, p=.061)$. However, linear regression shows that oral motor skill still has a significant relationship with vocabulary when the effect of PARCA scores is removed $(t=2.54, \mathrm{df}=2,19, p=$ .019)

It can be seen from Figure 2 that lower levels of oral motor skill almost invariably correspond to lower levels of language, while children with higher levels of oral motor skill have a range of language skills. This relationship was confirmed with a Chi-square test looking at the numbers of children who fell above and below 100 words on the CDI and a score of $50 \%$ on the complex oral movements tasks $($ Chi-sq $=4.02, \mathrm{df}=1, p=.045)$

\section{Discussion}

Study 2 shows that language and oral motor skill are linked in normal development; this is a replication and extension of very similar findings in a previous study with children aged 24 months (Alcock \& Gordon, 2002). This link is separate from the link between cognitive and language abilities, and is highly relevant for theories of language impairment: if poor oral motor skill can contribute to poor language, regardless of a child's cognitive skill, for some children who appear to have cognitive skill in the typical range, poor oral motor skill could lead to poor speech and language skills.

There are a number of explanations for this link. It may be that children who have good imitation abilities perform well on both language tests and oral motor tests.
In this study, language and cognitive skills were not assessed in the laboratory but by the parent, based on their observation of the child's language at home. These measures therefore did not depend directly on imitative ability, but language skill is still associated with oral motor skill, and to some extent with cognitive ability. Gross motor skill, in contrast, was assessed in the laboratory using both imitation and command to elicit movements, yet did not correlate with language. In addition, not all imitated movements had a relationship with language: in Study 1, simple, single movements performed to imitation were not impaired even in the most severely aphasic individuals; and in Study 2, the same simple movements did not show a significant relationship to language ability.

In our previous study (Alcock \& Gordon, 2002), a stronger relationship was found between oral motor skill and grammatical morphemes and words, than between oral motor skill and content words. In the current study the correlation was also slightly higher between complex oral movements and function words than content words. This is interesting given the particular difficulties reported by some observers with grammatical parts of speech, by children with SLI (Van der Lely, 1993). One possible explanation for this particular finding is that function words, and grammatical morphemes, are generally shorter words in English, as well as being unstressed. Where, say, a child can pronounce less than half the phonemes in a word, and that word has several phonemes (e.g. "elephant"), the result (e.g./عfə/) will be more comprehensible if the word has three phonemes (e.g. "that"), and the child can only pronounce one (e.g./?æ/). Parents may thus miss those attempts at shorter words a child is

\section{Oral motor and language scores}

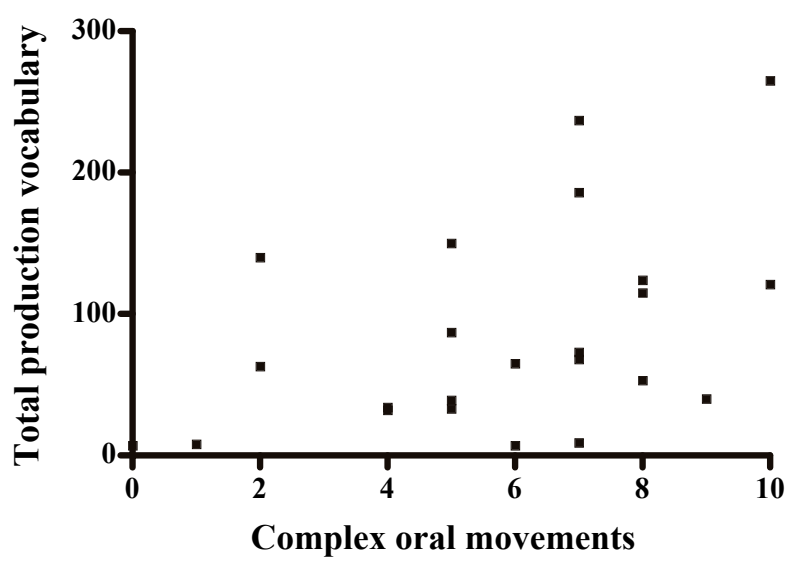

Figure 2. Scatter plot of complex oral motor skill and vocabulary on the CDI 
in fact making. Alternatively, children could be aware of their less intelligible attempts at words, and could miss out shorter words where they find their own productions are not as close to the target.

\section{Conclusions}

Previous studies of the link between oral motor skills and language have tended to look at simple movements more closely resembling eating movements (Moore \& Ruark, 1996), or fast repeated movements (Dworkin \& Culatta, 1985), neither of which seem to have a relationship with language development and disorders in these two studies. Our data suggest that more difficult oral movements are more closely related to language skills, possibly because they are more speech-like.

From these results, it seems that children who are poor at oral movements before they are two years old are also poor at language skills at the same age. Children who are good at oral motor skills may however be anywhere on the spectrum of language use. This implies that oral motor skills are a necessary, but not sufficient, prerequisite for good language skills. It is possible that this will translate into prediction of later language use by earlier oral motor skills - planned follow-up of the same children when they are three years old will be able to tell us if this is the case. In addition, we need to know more about how oral motor skills develop in young children, before we can investigate further the link between oral motor skills and language development and impairments.

\section{Acknowledgements}

Study 1 was supported by an MRC PhD studentship to the author, and was carried out as part of my DPhil thesis at Oxford University. Study 2 was supported by an ESRC small grant (RES-000-22-0054) to the author. Data for study 2 were collected by Kirsty Krawczyk at Lancaster University.

\section{Correspondence}

Katie Alcock • Department of Psychology, University of Lancaster, Fylde College, Lancaster LA1 4YF • E-mail: k.j.alcock@lancaster.ac.uk

\section{References}

Adams, L. (1998). Oral-motor and motor-speech characteristics of children with autism. Focus on Autism and Other Developmental Disabilities, 13(2), 108-112.

Alcock, K. J. (1995). Motor Aphasia: A Comparative Study. Unpublished DPhil thesis, Oxford University, Oxford.
Alcock, K. J. \& Gordon, E. (2002). Oral motor and language development. Paper presented at the Euresco Conference Series - Brain and Cognition in Human Infants, Acquafredda di Maratea, Italy.

Alcock, K. J., Passingham, R. E., Watkins, K. \& VarghaKhadem, F. (2000a). Pitch and timing abilities in inherited speech and language impairment. Brain \& Language, 75(1), 34-46.

Alcock, K. J., Passingham, R. E., Watkins, K. E. \& Vargha-Khadem, F. (2000b). Oral Dyspraxia in Inherited Speech and Language Impairment and Acquired Dysphasia. Brain \& Language, 75(1), 17-33.

Amato, J. J. \& Slavin, D. (1998). A preliminary investigation of oromotor function in young verbal and nonverbal children with autism. Infant Toddler Intervention, 8(2), 175-184.

Bates, E., Benigni, L., Bretherton, I., Carnaioni, L. \& Volterra, V. (1979). The Emergence of Symbols: Cognition and Communication in Infancy. New York: Academic Press.

Bates, E., Dale, P. S. \& Thal, D. (1995). Individual differences and their implications for theories of language development. In P. Fletcher \& B. MacWhinney (Eds.), The Handbook of Child Language (pp. 96-151). Oxford, UK: Blackwell.

Bates, E. \& Goodman, J. C. (1997). On the inseparability of grammar and the lexicon: Evidence from acquisition, aphasia and real-time processing. Language and Cognitive Processes, 12(5-6), 507-584.

Bayley, N. (1993). Bayley scales of infant development (2nd ed.). San Antonio, TX: Psychological Corporation.

Bishop, D.V.M. (2002). Motor immaturity and specific speech and language impairment: Evidence for a common genetic basis. American Journal of Medical Genetics, 114(1), 56-63.

Bizzozero, I., Costato, D., Della Sala, S., Papagno, C., Spinnler, H. \& Venneri, A. (2000). Upper and lower face apraxia: role of the right hemisphere. Brain, 123, 2213-2230.

Dworkin, J. P. \& Culatta, R. A. (1985). Oral structural and neuromuscular characteristics in children with normal and disordered articulation. Journal of Speech and Hearing Disorders, 50(2), 150-156.

Elman, J. L., Bates, E., Karmiloff-Smith, A., Johnson, M., Parisi, D. \& Plunkett, K. (1996). Rethinking Innateness: a Connectionist Perspective on Development. Cambridge, Mass.: MIT Press.

Felsenfeld, S., Broen, P. A. \& McGue, M. (1992). A 28-year follow-up of adults with a history of moderate phonological disorder: linguistic and personality results. Journal of Speech and Hearing Research, 35(5), 1114-1125. 
Fenson, L., Dale, P. S., Reznick, J. S. \& Bates, E. (1994). Variability in early communicative development. Monographs of the Society for Research in Child Development, 59, 1.

Fisher, S., Vargha-Khadem, F., Watkins, K. E., Monaco, A. P. \& Pembry, M. E. (1998). Localisation of a gene implicated in a severe speech and language disorder. Nature Genetics, 18, 168.

Fucile, S., Gisel, E. G. \& Lau, C. (2005). Effect of an oral stimulation program on sucking skill maturation of preterm infants. Developmental Medicine and Child Neurology, 47(3), 158-162.

Gopnik, M. \& Crago, M. B. (1991). Familial aggregation of a developmental language disorder. Cognition, 39, 1-50.

Hill, E. L. (2001). Non-specific nature of specific language impairment: a review of the literature with regard to concomitant motor impairments. International Journal of Language \& Communication Disorders, 36(2), 149-171.

Johnson, R. \& Harris, G. (2004). A preliminary study of the predictors of feeding problems in late infancy. Journal of Reproductive and Infant Psychology, 22(3), 183-188.

Karmiloff-Smith, A. (1998). Development itself is the key to understanding developmental disorders. Trends in Cognitive Sciences, 2(10), 389-398.

Kumin, L. \& Adams, J. (2000). Developmental apraxia of speech and intelligibility in children with Down syndrome. Down Syndrome Quarterly, 5(3), 1-7.

Kumin, L. \& Bahr, D. C. (1999). Patterns of feeding, eating and drinking in young children with Down syndrome with oral motor concerns. Down Syndrome Quarterly, 4(2), 1-8.

Landt, H. \& Ingervall, B. (1975). Oral ability to recognize forms and oral motor ability in 11-year-old children. Journal of Oral Rehabilitation, 2(1), 63-73.

Lewis, B. A., Freebairn, L. A., Hansen, A. J., Iyengar, S. K. \& Taylor, H. G. (2004). School-age follow-up of children with childhood apraxia of speech. Language Speech And Hearing Services In Schools, 35(2), 122140.

Masdeu, J. C. \& O’Hara, R. J. (1983). Motor aphasia unaccompanied by faciobrachial weakness. Neurology, 33, 519-521.

Mason, S. J., Harris, G. \& Blissett, J. (2005). Tube feeding in infancy: Implications for the development of normal eating and drinking skills. Dysphagia, 20(1), 46-61.

Mateer, C. \& Kimura, D. (1977). Impairment of nonverbal oral movements in aphasia. Brain and Language, 4, 262-276.
Moore, C. A. \& Ruark, J. L. (1996). Does speech emerge from earlier appearing oral motor behaviors? Journal of Speech and Hearing Research, 39(5), 1034-1047.

Naigles, L. (1990). Children use syntax to learn verb meanings. Journal of Child Language, 17(2), 357-374.

Page, J. \& Boucher, J. (1998). Motor impairments in children with autistic disorder. Child Language Teaching \& Therapy, 14(3), 233-259.

Pinker, S. (1995). The Language Instinct (1st ed.). New York: HarperPerennial.

Qvarnstrom, M. J., Jaroma, S. M. \& Laine, M. T. (1994). Changes in the peripheral speech mechanism of children from the age of 7 to 10 years. Folia Phoniatrica et Logopaedica, 46(4), 193-202.

Rogers, B. \& Arvedson, J. (2005). Assessment of infant oral sensorimotor and swallowing function. Mental Retardation and Developmental Disabilities Research Reviews, 11(1), 74-82.

Saudino, K. J., Dale, P. S., Oliver, B., Petrill, S. A., Richardson, V., Rutter, M. et al. (1998). The validity of parent-based assessment of the cognitive abilities of 2-year-olds. British Journal of Developmental Psychology, 16(3), 349-363.

Smith, A. \& Zelaznik, H. N. (2004). Development of Functional Synergies for Speech Motor Coordination in Childhood and Adolescence. Developmental Psychobiology, 45(1), 22.

Spender, Q., Dennis, J., Stein, A. \& Cave, D. (1995). Impaired oral-motor function in children with Down's syndrome: A study of three twin pairs. European Journal of Disorders of Communication, 30(5), 77-87.

Stackhouse, J. \& Snowling, M. (1992). Developmental verbal dyspraxia II: A developmental perspective on two case studies. European Journal of Disorders of Communication, 27, 35-54.

Stark, R. E. \& Blackwell, P. B. (1997). Oral volitional movements in children with language impairments. Child Neuropsychology, 3(2), 81-97.

Thal, D. J., Bates, E., Goodman, J. \& Jahn-Samilo, J. (1997). Continuity of language abilities: An exploratory study of late- and early-talking toddlers. Developmental Neuropsychology, 13, 239-273.

Van der Lely, H. K. (1993). Specific language impairment in children: Research findings and their therapeutic implications. European Journal of Disorders of Communication, 28(3), 247-261.

Vargha-Khadem, F., Watkins, K., Alcock, K. J., Fletcher, P. \& Passingham, R. (1995). Praxic and nonverbal cognitive deficits in a large family with a genetically transmitted speech and language disorder. Proceedings of the National Academy of Sciences of the United States of America, 92(3), 930-933. 
Watkins, K. E., Vargha-Khadem, F., Ashburner, J., Passingham, R. E., Connelly, A., Friston, K. J. et al. (2002). MRI analysis of an inherited speech and language disorder: structural brain abnormalities. Brain, 125, 465-478.

Werker, J. F., Fennell, C. T., Corcoran, K. M. \& Stager, C. L. (2002). Infant's ability to learn phonetically similar words: Effects of age and vocabulary size. Infancy, 3(1), 1-30.
Yaruss, J. S. \& Logan, K. J. (2002). Evaluating rate, accuracy, and fluency of young children's diadochokinetic productions: a preliminary investigation. Journal of Fluency Disorders, 27(1), 65-86.

\section{Appendix: Oral motor scale for children under 39 months}

\section{Single Movements}

Each item was scored on the following scale, and the scores were totalled:

0 - No Attempt

1 - Attempted

2 - Completed Successfully

1) Open the mouth wide (copy a puppet)

2) Turn down the corners of the lips (frowning - copy the experimenter)

3) Close the lips tightly together (copy puppet)

4) Stretch the lips wide (smiling - copy experimenter)

5) Blow the cheeks out (copy experimenter)

6) Stick the tongue out (copy puppet)

7) Bring the front teeth together (biting a plastic baby spoon)

8) Make the lips round and blow, child is scored on ability to make the round shape and control the blowing (blowing soap bubbles using commercial or homemade toy)

9) Kissing (place flavoured lip salve and press lips together over a piece of flexible clear plastic - both lips should make a mark on the plastic)

10) Place honey on lips and lick off (use other sticky food if necessary - copy experimenter and lick sideways, not just moving tongue in and out)

Numbers 5, 6, 8, 9, and 10 are classified as complex movements (requiring more than one set of muscles).

\section{Repeated Movements}

For all tests: the experimenter starts slowly and then speeds up. The movements were timed using the slow playback (frame by frame) function of a video editing machine but the maximum time of 10 seconds for each set was also timed using a stop watch, during the testing session. If the child stops or slows down before $10 \mathrm{sec}-$ onds were over they were encouraged to continue but the period of continuous repetition was counted even if this was less than 10 seconds.

Either a puppet or the experimenter's demonstration was used for all of the repetition tasks, which were as follows:

1) Open and close the mouth repeatedly

2) Stick the tongue out and in repeatedly

3) Make an "ah" sound in the throat repeatedly

4) Alternating Movements: open the mouth, then stick the tongue out, then close the mouth

Each item was scored:

$0=$ No attempt

$1=$ Any Attempt

2 = Completes for $10 \mathrm{sec}$

In addition the total number of correct movements in the total time used, or 10 seconds (whichever is shorter), the total number of completed plus attempted movements in the same time (all movements), and the time used, were all noted. From these was calculated the rate of performing correct movements, the rate of performing all movements, and the ratio of correct to all movements. 